Proc. Estonian Acad. Sci. Biol. Ecol., 2006, 55, 1, 61-81

\title{
Model calculations of diffuse attenuation coefficient spectra in lake waters
}

\author{
Birgot Paavel $^{\mathrm{a}}$, Helgi Arst ${ }^{\mathrm{a}}$, Anu Reinart ${ }^{\mathrm{b}}$, and Antti Herlevi ${ }^{\mathrm{c}}$ \\ ${ }^{a}$ Estonian Marine Institute, University of Tartu, Mäealuse 10A, 12618 Tallinn, Estonia \\ b Tartu Observatory, 60602 Tõravere, Estonia \\ c Tekes, National Technology Agency, Kyllikinportti 2, P.O. Box 69, FIN-00101, Helsinki, Finland \\ Received 15 February 2005, in revised form 26 April 2005

\begin{abstract}
The reliability of the models elaborated for recreating the spectra of the light attenuation coefficient, $K_{\mathrm{d}, \lambda}$, on the basis of its measured values at 1-3 wavelengths was studied. The coefficients of the "one-point" (490 nm) model, elaborated earlier by A. Reinart and A. Herlevi, were tested and approved using 43 new spectra of underwater irradiance measured in 1999-2000. A new version (named C-model) allowing recreation of the spectrum of $K_{\mathrm{d}, \lambda}$ on the basis on its measured values at three wavelengths was elaborated and tested by statistical analysis. The C-model was found to enable to reconstruct the spectra of $K_{\mathrm{d}, \lambda}$ with high reliability. Both models gave truthful values of $K_{\mathrm{d}, \mathrm{PAR}}$ (mean value of $K_{\mathrm{d}, \lambda}$ in the region $400-700 \mathrm{~nm}$ ). For the estimation of the reliability of the experimental initial data, the values of $K_{\mathrm{d}, \lambda}$ derived from in situ measurements by an underwater spectrometer LI-1800 UW and an instrument ac-9 were compared. The results showed that $K_{\mathrm{d}, \lambda}(\mathrm{ac}-9)$ is mostly lower than $K_{\mathrm{d}, \lambda}(\mathrm{LI}-1800 \mathrm{UW})$, the differences increasing with wavelength.
\end{abstract}

Key words: marine optics, limnology, underwater light field, light attenuation coefficient.

\section{INTRODUCTION}

Underwater solar light can be considered to play a dual role: (1) it is necessary for living organisms and (2) it serves as additional information for measurements of the aquatic environment's properties. Relying on the values of underwater irradiance at different wavelengths one can qualitatively estimate the contribution of different optically active substances (OAS) in the attenuation of light in water (e.g. small values of irradiance in the violet and blue regions of the spectrum imply that the dissolved organic matter is dominating, the local minimum between 670 and $680 \mathrm{~nm}$ shows that the role of phytoplankton is noticeable). Attenuation

*Corresponding author, Helgi.Arst@ut.ee 
of underwater light is important for a wide range of processes. The interactions of light availability, its spectral distribution, and the physiology of phytoplankton impose fundamental constraints on the rate of primary production of a water column (Platt et al., 1984; Gallegos et al., 1990; Kirk, 1996). As shown by model calculations and numerous field measurements (Kirk, 1996), underwater light is an important factor in the formation of vertical distribution and abundance of phytoplankton as well as bottom vegetation. According to Sathyendranath et al. (1989), Smith et al. (1989), and Kyewalyanga et al. (1992) it is the spectral distribution of underwater irradiance $\left(E_{\mathrm{d}}\right)$ that is critical for determining the primary production by model calculations. However, in many limnological studies, profiles of underwater irradiance in the region of photosynthetically active radiation (PAR, 400-700 nm) are determined on the basis of the incident irradiance $E_{\mathrm{d}, \mathrm{PAR}}\left(\right.$ inc) and the diffuse attenuation coefficient $K_{\mathrm{d}, \mathrm{PAR}}$. In most cases widely available PAR sensors are used for obtaining these data, but some authors determine $K_{\mathrm{d}, \mathrm{PAR}}$ even by indirect estimates by Secchi depth (Chow-Fraser, 1998; Stefan et al., 1998). Errors in vertical profiles of $E_{\text {d.PAR }}$ caused by using this averaged coefficient were estimated in Arst et al. (2000). It was shown that in very clear waters errors can exceed even $100 \%$ and in turbid waters $50 \%$, the depth of the maximum error depending on the water type.

Today we can find several instruments for in situ determination of the spectral composition of underwater $E_{\mathrm{d}, \lambda}$, from which the respective spectra of $K_{\mathrm{d}, \lambda}$ can be derived. However, rather often we have data only for one or a few channels, e.g. measurements by satellites, BIC-2104 radiometer (Biospherical Instruments Inc.), absorption and beam attenuation meter "ac-9" (WET Labs, Inc., 1995), or there are cases where the values of $E_{\mathrm{d}, \lambda}$ in the region of $400-440 \mathrm{~nm}$ are so low that their determination is extremely difficult (Reinart \& Herlevi, 1999; Herlevi, 2002; Arst et al., 2002; Reinart et al., 2004). For this reason model calculations allowing determination of the spectra of the diffuse attenuation coefficient $K_{\mathrm{d}, \lambda}$ are of great importance.

When light conditions and inherent optical properties of water are known, $K_{\mathrm{d}, \lambda}$ could be calculated solving radiative transfer equations in water (Mobley, 1994; Kirk, 1981, 1996). It is possible to estimate $K_{\mathrm{d}, \lambda}$ spectra also from the measurements of inherent optical properties. There exist different calculation methods that are suitable for the assessment of $K_{\mathrm{d}, \lambda}$ spectra. In the model by Arst et al. (2002) the initial data are spectra of the beam attenuation coefficient measured from water samples in laboratory and values of incident solar irradiance. Reinart \& Herlevi (1999) presented an analytical form for spectra of $K_{\mathrm{d}, \lambda}$, suitable for different types of lakes (method is analogous to that by Austin \& Petzold (1986) elaborated for oceanic waters). The model allows calculating the spectra of $K_{\mathrm{d}, \lambda}$ (with $10 \mathrm{~nm}$ step over the range $400-700 \mathrm{~nm}$ ) on the basis of a measured irradiance profile in one reference wavelength.

The first task of the present study was to verify the model of Reinart \& Herlevi (1999) taking into account new data obtained by in situ measurements of underwater irradiance. Our main purpose, bearing in mind practical needs, was to 
elaborate a new, improved model for recreating the $K_{\mathrm{d}, \lambda}$ spectra using its three spectral values determined by the underwater radiometer BIC-2104. As an additional task, we compared the $K_{\mathrm{d}, \lambda}$ values obtained on the basis of LI-1800 UW data with those calculated on the basis of ac-9 data.

\section{MATERIALS AND METHODS}

\section{Analytical expression for diffuse attenuation coefficient of lakes}

The diffuse spectral attenuation coefficient for downwelling irradiance, $K_{\mathrm{d}, \lambda}$, is defined as follows (Preisendorfer, 1961; Jerlov, 1968; Dera, 1992):

$$
K_{\mathrm{d}, \lambda}(z)=-\frac{1}{E_{\mathrm{d}, \lambda}(z)} \frac{\mathrm{d} E_{\mathrm{d}, \lambda}(z)}{\mathrm{d} z}
$$

where $\lambda$ is the wavelength and $E_{\mathrm{d}, \lambda}$ is the downwelling irradiance at the depth $z$. To calculate $K_{\mathrm{d}, \lambda}$ for a vertically homogeneous water layer from the depth $z_{1}$ to $z_{2}$ the following formula is applied in practice:

$$
K_{\mathrm{d}, \lambda}\left(z_{1}, z_{2}\right)=-\frac{1}{z_{2}-z_{1}} \ln \left[\frac{E_{\mathrm{d}, \lambda}\left(z_{2}\right)}{E_{\mathrm{d}, \lambda}\left(z_{1}\right)}\right] .
$$

Note that Eq. 2 is derived for monochromatic radiation; it works quite well for narrow spectral intervals, but gives only approximate results for integral radiation (Kirk, 1996; Arst et al., 2000). When $z$ is measured in m, $K_{\mathrm{d}, \lambda}$ is expressed in $\mathrm{m}^{-1}$.

In an optically unstratified water body $\left(K_{\mathrm{d}, \lambda}\right.$ practically does not depend on depth), the underwater irradiance can be calculated by the following formula:

$$
E_{\mathrm{d}, \lambda}(z)=\left(1-A_{\lambda}\right) E_{\mathrm{d}, \lambda}^{+}(0) \exp \left(-K_{\mathrm{d}, \lambda} z\right)
$$

where $A_{\lambda}$ is albedo and $E_{\mathrm{d}, \lambda}^{+}(0)$ is the incident irradiance. In optically stratified water bodies, $K_{\mathrm{d}, \lambda}$ in Eq. 3 can be considered as the diffuse attenuation coefficient averaged over the layer from 0 to $z$. As is known, on the basis of spectral data of $E_{\mathrm{d}, \lambda}$ in the PAR region $(400-700 \mathrm{~nm})$, it is possible to determine the corresponding value of $E_{\mathrm{d}, \mathrm{PAR}}$ :

$$
E_{\mathrm{d}, \mathrm{PAR}}=\int_{400}^{700} E_{\mathrm{d}, \lambda} \mathrm{d} \lambda
$$


From the vertical profile of $E_{\mathrm{d}, \mathrm{PAR}}$ the value of $K_{\mathrm{d}, \mathrm{PAR}}$ can be estimated.

The model by Reinart \& Herlevi (1999) was quantified on the basis of spectral measurements of underwater light using the spectroradiometer LI-1800 UW (LI-COR, Inc., 1984). It is a portable instrument capable of scanning the irradiance in the water between 300 and $850 \mathrm{~nm}$ with $2 \mathrm{~nm}$ intervals. There were 49 measurement series, carried out in 14 Estonian and Finnish lakes in 1995 and 1997. In this study, relying on the measured irradiance profiles, the corresponding spectra of the diffuse attenuation coefficient were determined. Then, using statistical methods, an algorithm and its spectral parameters were found suitable for recreating the diffuse attenuation coefficient spectra for a water body on the basis of known values of $K_{\mathrm{d}}(490 \mathrm{~nm})$, i.e. $\lambda_{\mathrm{r}}=490 \mathrm{~nm}$ was taken as a reference wavelength. This equation and the respective spectral coefficients (for the PAR region) are shown below (Eq. 5 and Table 1). For brevity, let us name this method the "490-model".

$$
K_{\mathrm{d}}(\lambda)=J(\lambda)+M(\lambda) K_{\mathrm{d}}(490) .
$$

The wavelength $490 \mathrm{~nm}$ was chosen because the ocean colour sensors SeaWiFS and MODIS provide $K_{\mathrm{d}}(490)$ as a standard Level 2 product (http://oceancolor.gsfc.nasa.gov/), and many widely used in situ instruments have this waveband. Then, using Eq. 5 and the "satellite" value of $K_{\mathrm{d}}(490)$, we can recreate the whole spectrum in the PAR region. This is especially important for turbid and humid lakes where in the violet and blue parts of the spectrum the values of the underwater light are often very low and practically no measurement data can be obtained by technical reasons.

Table 1. Values of the intercept $J(\lambda)( \pm 0.04)$ and slope parameters $M(\lambda)( \pm 0.01)$ for analytical expression of $K_{\mathrm{d}}(\lambda)$ by Eq. 4 (taken from Reinart \& Herlevi, 1999)

\begin{tabular}{l|c|c|c|c|c|c|c|c}
\hline$\lambda, \mathrm{nm}$ & $J(\lambda)$ & $M(\lambda)$ & $\lambda, \mathrm{nm}$ & $J(\lambda)$ & $M(\lambda)$ & $\lambda, \mathrm{nm}$ & $J(\lambda)$ & $M(\lambda)$ \\
\hline 400 & 0.58 & 2.20 & 510 & -0.07 & 0.87 & 610 & 0.03 & 0.51 \\
410 & 0.52 & 2.00 & 520 & -0.08 & 0.80 & 620 & 0.08 & 0.50 \\
420 & 0.44 & 1.79 & 530 & -0.09 & 0.74 & 630 & 0.10 & 0.47 \\
430 & 0.37 & 1.66 & 540 & -0.10 & 0.68 & 640 & 0.12 & 0.45 \\
440 & 0.28 & 1.56 & 550 & -0.11 & 0.64 & 650 & 0.16 & 0.43 \\
450 & 0.22 & 1.37 & 560 & -0.13 & 0.61 & 660 & 0.21 & 0.43 \\
460 & 0.18 & 1.24 & 570 & -0.14 & 0.58 & 670 & 0.26 & 0.44 \\
470 & 0.11 & 1.14 & 580 & -0.12 & 0.56 & 680 & 0.31 & 0.43 \\
480 & 0.06 & 1.06 & 590 & -0.06 & 0.53 & 690 & 0.40 & 0.38 \\
490 & 0.00 & 1.00 & 600 & 0.00 & 0.52 & 700 & 0.53 & 0.33 \\
500 & -0.04 & 0.93 & & & & & &
\end{tabular}


A generalized version of Eq. 5 is presented in Eq. 6 (Reinart \& Herlevi, 1999), where the spectra of $K_{\mathrm{d}, \lambda}$ can be recreated taking the reference wavelength not only at $490 \mathrm{~nm}$, but at any other wavelength. Note that for each case the same coefficients as shown in Table 1 have to be used.

$$
K_{\mathrm{d}}\left(\lambda_{2}\right)=J\left(\lambda_{2}\right)+\left[K_{\mathrm{d}}\left(\lambda_{1}\right)-J\left(\lambda_{1}\right)\right] \frac{M\left(\lambda_{2}\right)}{M\left(\lambda_{1}\right)} .
$$

\section{New spectral irradiance measurements}

In 1999-2000 we carried out additional (44 series) in situ measurements of underwater irradiance using the spectroradiometer LI-1800 UW. In the present study we used earlier (1995 and 1997) as well as new (1999-2000) data sets. The lakes under investigation were located in Estonia and Southern Finland, in the area with geographical coordinates ranging from $58^{\circ} \mathrm{N}$ to $62^{\circ} \mathrm{N}$ and from $24^{\circ} \mathrm{E}$ to $27^{\circ} \mathrm{E}$. Table 2 gives information on the lakes studied in these periods. The spectral distribution of underwater irradiance was determined with the underwater spectroradiometer (LI-1800 UW). Radiation enters the detector through a cosine

Table 2. Estonian and Finnish lakes studied in both measurement periods using an underwater spectrometer LI-1800 UW and simultaneously the instrument ac-9. The values of $K_{\mathrm{d}, \mathrm{PAR}}$, averaged from measurements in each lake, are also shown. $N$ is the number of measurement series. $\mathrm{E}$ and $\mathrm{F}$ stand respectively for Estonian and Finnish

\begin{tabular}{ll|l|l|c|c}
\hline \multicolumn{1}{c|}{ Lake } & \multicolumn{1}{c|}{$\begin{array}{c}\text { Limnological } \\
\text { type }\end{array}$} & $\begin{array}{c}K_{\mathrm{d}, \mathrm{PAR}} \\
(\mathrm{aver})\end{array}$ & $\begin{array}{c}N(1995 \\
\& 1997)\end{array}$ & $\begin{array}{c}N(1999 \\
\& 2000)\end{array}$ & $\begin{array}{c}N \\
\text { (ac-9) }\end{array}$ \\
\hline Enajärvi (F) & Eutrophic & 4.13 & 0 & 1 & 1 \\
Koorküla Valgjärv (E) & Oligotr./Mesotr. & 0.74 & 1 & 4 & 3 \\
Kurtna Nõmmjärv (E) & Dyseutrophic & 1.32 & 2 & 0 & 0 \\
Lammi Pääjärvi (F) & Mesotrophic & 2.79 & 6 & 4 & 4 \\
Lohjanjärvi (F) & Eutrophic & 3.40 & 0 & 6 & 4 \\
Nohipalu Valgjärv (E) & Oligotr./Mesotr. & 0.97 & 3 & 3 & 4 \\
Paukjärv (E) & Oligotrophic & 0.66 & 1 & 2 & 3 \\
Päijänne (F) & Oligotrophic & 1.08 & 3 & 4 & 4 \\
Tuusulanjärvi (F) & Hypertrophic & 5.33 & 3 & 4 & 4 \\
Uljaste (E) & Semidystrophic & 2.11 & 2 & 0 & 0 \\
Valkeakotinen (F) & Dystrophic & 5.18 & 3 & 0 & 0 \\
Verevi (E) & Hypertrophic & 1.64 & 5 & 4 & 2 \\
Vesijärvi (F) & Eutrophic & 1.13 & 7 & 4 & 5 \\
Võrtsjärv (E) & Eutrophic & 3.37 & 4 & 3 & 4 \\
Äntu Sinijärv (E) & Alkalitrophic & 0.25 & 1 & 0 & 0 \\
Ülemiste (E) & Hypertrophic & 3.50 & 0 & 4 & 4
\end{tabular}


receptor, which enables a 180-degree uptake. The absolute calibration error in the range of visible light is $3-5 \%$ and in the ultraviolet part of the spectrum around $10 \%$. LI-1800 UW measures rather slowly (a full spectral scan takes about $18 \mathrm{~s}$ ) and irradiance may change during one scan and between scans because of variation in cloud conditions. To account for these fluctuations, a LI-200SA pyranometer (spectral range 400-1100 nm, LI-COR, Inc.) with a LI-1400 DataLogger (LI-COR, Inc.) was used to normalize the spectra. Four scans at each depth were averaged to improve the representativeness of the results.

Depth averaged values of $K_{\mathrm{d}, \lambda}$ (Eq. 2) were obtained using least-squares exponential curve fitting to the vertical irradiance profiles. In the present study mostly the values of $K_{\mathrm{d}, \lambda}$ for a water layer from a depth of $0.5 \mathrm{~m}$ to $2 \mathrm{~m}$ were used. However, there were cases when the values of $E_{\mathrm{d}, \lambda}$ (from the surface down to 1-2 m) had strong fluctuations (Arst et al., 1999; Arst, 2003) and then a thinner and deeper layer was used. In some other cases $E_{\mathrm{d}, \lambda}$ decreased very quickly with depth (especially in the blue region of the spectrum) and irradiance values were beyond the sensitivity limit $\left(3 \times 10^{-5} \mathrm{~W} \mathrm{~m}^{-2} \mathrm{~nm}^{-1}\right)$ of the spectrometer. In these cases a thinner layer (mostly around $1 \mathrm{~m}$ ) was used. Measurements were carried out twice per year, in May or June and in August, mostly around noon.

Adding these data to the data set obtained in 1995-1997 we got a combined data set, containing $84 K_{\mathrm{d}, \lambda}$ spectra, derived from LI-1800 UW measurements (Table 2). Actually we had 91 spectra (including one additional lake, dark brown L. Nohipalu Mustjärv in Estonia). However, in four cases the water transparency was so low that the LI-1800 UW data in the region 400-500 nm were missing. In three cases the measured $E_{\mathrm{d}, \lambda}$ spectra were highly fluctuating with wavelength, the corresponding $K_{\mathrm{d}, \lambda}$ spectra were also fluctuating and obviously determined with large errors. Thus, we left these 7 spectra out from our data set.

\section{Validation of 490-model results with field data and independent calculations}

First we applied Eq. 5 and the coefficients presented in Table 1 to the new measurements (43 series in 1999-2000, shown in Table 2). Our purposes were (a) to find out whether there is a need to change the coefficients or not; and (b) to investigate the errors of modelled $K_{\mathrm{d}, \lambda}$ values (it was provisionally assumed that the measurement results were totally reliable). We calculated different kinds of errors, described by the following formulas:

$$
\begin{gathered}
\mathrm{AE}=\frac{1}{N} \sum_{1}^{N}\left(K_{\mathrm{d}}(\text { meas })-K_{\mathrm{d}}(\text { calc })\right), \\
\mathrm{AAE}=\frac{1}{N} \sum_{1}^{N} \mid K_{\mathrm{d}}(\text { meas })-K_{\mathrm{d}}(\text { calc }) \mid
\end{gathered}
$$




$$
\begin{gathered}
\mathrm{RE}=\frac{1}{N} \sum_{1}^{N} \frac{2\left(K_{\mathrm{d}}(\text { meas })-K_{\mathrm{d}}(\text { calc })\right)}{\left.\left(K_{\mathrm{d}} \text { (meas }\right)+K_{\mathrm{d}}(\text { calc })\right)}, \\
\mathrm{ARE}=\frac{1}{N} \sum_{1}^{N} \frac{\left.2 \mid K_{\mathrm{d}} \text { (meas }\right)-K_{\mathrm{d}}(\text { calc }) \mid}{\left.K_{\mathrm{d}} \text { (meas }\right)+K_{\mathrm{d}}(\text { calc })} .
\end{gathered}
$$

$\mathrm{AE}, \mathrm{AAE}, \mathrm{RE}$, and ARE are respectively absolute error, "absolute" absolute error, relative error, and "absolute" relative error. Including AAE and ARE is necessary, because differences between measured and calculated values usually change both to plus and minus direction. In some cases it can lead to the result that the averaged values of $\mathrm{AE}$ and $\mathrm{RE}$ are close to zero although actually there are great (positive and negative) errors in many individual cases.

Next we investigated how the $K_{\mathrm{d}, \lambda}$ spectra depend on the choice of reference wavelength. We repeated the calculations of $K_{\mathrm{d}, \lambda}$ using Eq. 6 for three reference wavelengths $\left(\lambda_{\mathrm{r}}=412,555\right.$, and $\left.665 \mathrm{~nm}\right)$. These wavelengths are the central points of three channels of the underwater radiometer BIC-2104, which has already been used for measurements in many lakes (Reinart et al., 2004). The results obtained by the BIC-2104 are not included into the present paper, but a special study will be performed in the future.

In limnology not only spectral instruments but also multi-band instruments (analogous to the BIC-2104) are used. As different OAS have specific spectral effects on $K_{\mathrm{d}, \lambda}$, it might be better to use not one but several reference wavelengths. As we already have a data set measured by the BIC-2104 (Reinart et al., 2004) and the measurements will continue, we chose the wavelengths corresponding to three channels of the BIC-2104 (in principle, one can use any other wavelengths in the PAR region). Thus, we elaborated a method allowing recreation of the spectrum of $K_{\mathrm{d}, \lambda}$ on the basis of its values at three wavelengths. As this method is our main result, it is described in the section "Results and discussion".

\section{Comparison of the $K_{\mathrm{d}, \lambda}$ values calculated on the basis of LI-1800 UW and ac-9 measurement data}

When estimating the reliability of the model by comparing the results with the measured spectra, we have to remember that these two databases are not independent. As the value of $K_{\mathrm{d}, \lambda}$ at the reference wavelength is taken directly from the measured spectra, all the calculated values in the PAR region are more or less influenced by the measured $K_{\mathrm{d}, \lambda}\left(\lambda_{\mathrm{r}}\right)$. Thus, it is of interest to compare the measured spectra of $K_{\mathrm{d}, \lambda}$ with those determined on the basis of simultaneous measurements by some other device. For this purpose we used $42 K_{\mathrm{d}, \lambda}$ spectra derived from simultaneous measurements (in 1997 and 1999-2000) with the instrument ac-9 (Table 2). 
This instrument is a spectral attenuation/absorption meter (measures the values of attenuation and absorption coefficients, $c$ and $a$ ) that uses nine bandpass optical filters to spectrally discriminate the light from a tungsten lamp (Herlevi et al., 1999). The wavelengths used are 412, 440, 488, 510, 532, 555, 650,676 , and $715 \mathrm{~nm}$ (in 2000 the channel at $532 \mathrm{~nm}$ was replaced by a channel at $630 \mathrm{~nm}$ ). The instrument is calibrated to provide a reading of 0.0 for each channel in clean fresh water. This means that for determining the real values of the coefficients, we have to add the respective $c$ or $a$ of the clean water to the readings of ac-9.

The values of $K_{\mathrm{d}, \lambda}$ at all ac-9 wavebands can be calculated on the basis of measured absorption and attenuation coefficients $(a$ and $c$ ) using algorithms derived by Kirk $(1989,1996)$. In these formulas the initial data are $a$ and $b$ (scattering coefficient), but because $c=a+b$ we can use Kirk's formulas replacing $b$ by $c-a$. There are different formulas for clear sky and overcast cases. We used the last one, because (1) often the sky was partially cloudy (or overcast), (2) the "clear" variant needs the data on the solar zenith angle, and in our cases (solar angle mostly between 40 and $60^{\circ}$ ) the results by two formulas differ only slightly. Thus, the calculations were made using Kirk's formula in the following form:

$$
K_{\mathrm{d}, \lambda}=1.168 \sqrt{a_{\lambda}^{2}+0.162\left(c_{\lambda}-a_{\lambda}\right) a_{\lambda}} .
$$

Naturally, the data for 9 channels from 412 to $715 \mathrm{~nm}$ do not describe the full spectrum in detail, but still give a good opportunity to compare the spectral values.

Comparing the data sets of $K_{\mathrm{d}, \lambda}$ calculated on the basis of simultaneous measurements with the LI-1800 UW and ac-9, Herlevi (2002) made a conclusion that Kirk's formulas are unsuitable for lake waters. He proposed a generalized formula

$$
K_{\mathrm{d}, \lambda}=A \sqrt{B a_{\lambda}^{2}+C a_{\lambda} b_{\lambda}},
$$

where the coefficient $A=1.2$, but the values of $B$ and $C$ depend on the optical classes or the inherent properties of the water. We made additional calculations by Eq. 12 using the following values of $B$ and $C$, taken from Herlevi (2002):

(1) $\quad c_{\lambda}=0-1.99 \mathrm{~m}^{-1}, \quad$ then $B=0.94 \quad$ and $C=0.28 ;$
(2) $\quad c_{\lambda}=2.0-5.99 \mathrm{~m}^{-1}$, then $B=0.97$ and $C=0.42 ;$
(3) $\quad c_{\lambda}=6.0-25 \mathrm{~m}^{-1}$, then $B=0.73$ and $C=0.55$.




\section{RESULTS AND DISCUSSION}

\section{Analysis of results obtained using the 490-model}

As mentioned before, we calculated the errors AE, AAE, RE, and ARE (respectively by Eqs 7-10). Lake Äntu Sinijärv was left out from these calculations because the 490-model gave here extremely high RE and the values of $K_{\mathrm{d}, \lambda}$ in the region 530-590 nm were negative. However, L. Äntu Sinijärv (with Secchi disc transparency about $13 \mathrm{~m}$ ) is an exceptionally clear lake, peculiar in our study area. The spectra of averaged over the whole measurement series AAE and ARE are shown in Fig. 1. We can see that the values of ARE for the period 1999-2000 are smaller than those for 1995-1997 but the curves of ARE are very similar. The maximum values of ARE are about $18-21 \%$ and located in the region $570-670 \mathrm{~nm}$. As can be expected, ARE was highest in the orange and red regions of the spectrum, but the maximum values of AAE were observed between 400 and $430 \mathrm{~nm}$. Because the values of AAE and ARE for the period 1999-2000 were almost the same as for 1995-1997 (even a little lower), we can conclude that there is no need to recalculate the coefficients $J(\lambda)$ and $M(\lambda)$ (Table 1).

Figure 1 gives generalized information for all lakes together. However, it is of interest to find out the characteristic features of each lake separately. In Fig. 2 the mean values of the relative error (RE) for 12 lakes are shown (we included only lakes that had at least three measurement series). We can see that in the blue region of the spectrum the clear-water lakes $\left(K_{\mathrm{d}, \mathrm{PAR}}<2 \mathrm{~m}^{-1}\right)$ are often characterized by negative values of RE, but in the interval $500-700 \mathrm{~nm}$ RE is mostly positive

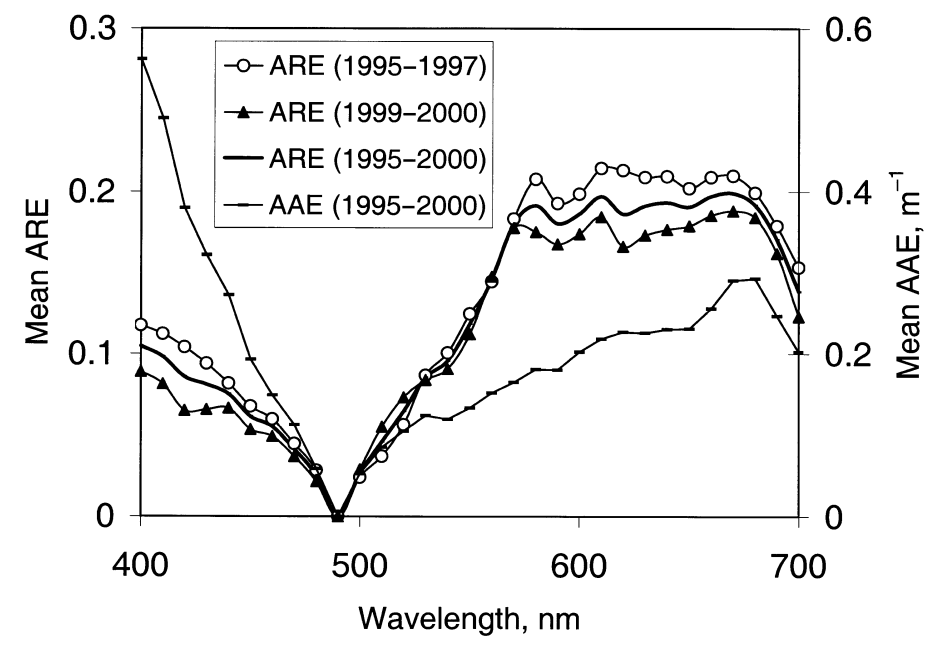

Fig. 1. Spectral distribution of mean values of the "absolute" absolute error, AAE and "absolute" relative error, ARE (correspondingly by Eqs 8 and 10). The results were obtained using the 490-model and measurements in 1995-2000. 


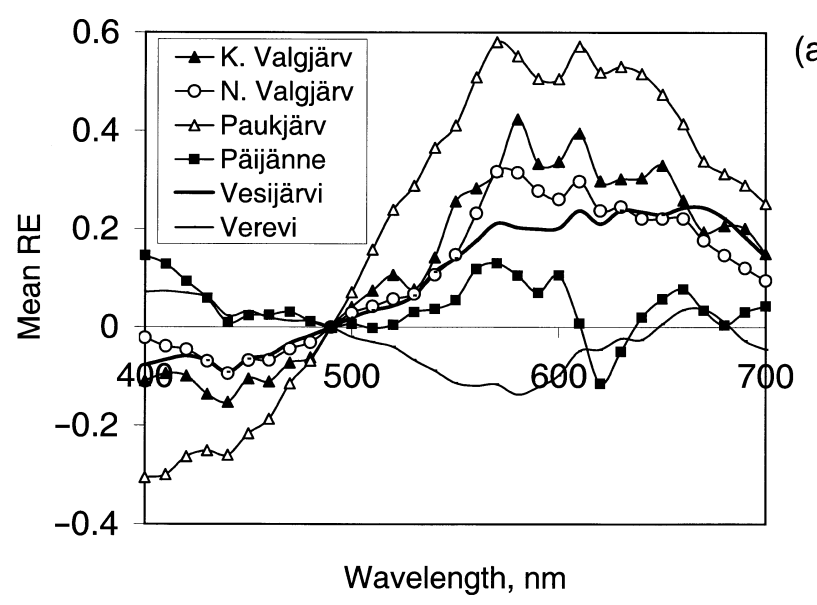

(a)

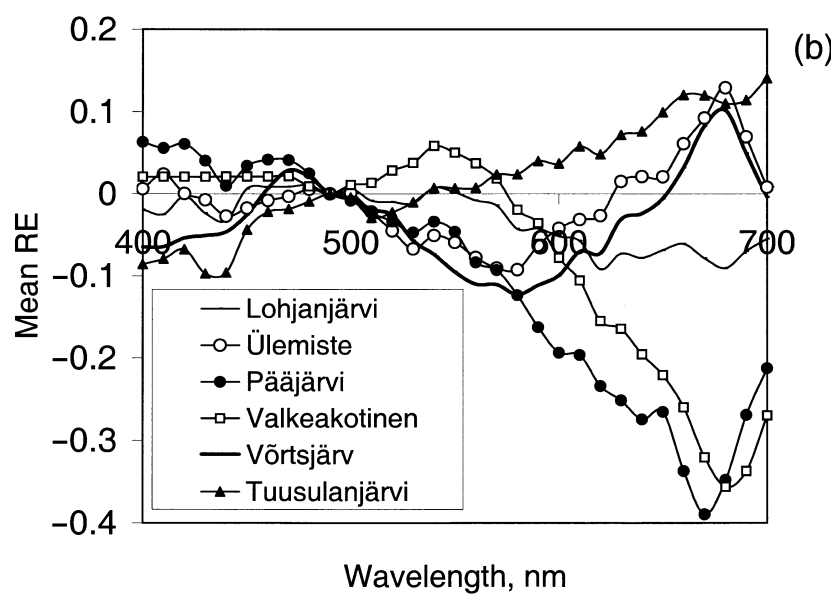

Fig. 2. Spectral distribution of mean values of the relative error, RE (Eq. 9), calculated separately for 12 lakes (on the basis of 3-11 spectra): (a) lakes where $K_{\text {d.PAR }}$ (aver) $<2 \mathrm{~m}^{-1}$, (b) lakes where $K_{\text {dPAR }}($ aver $)>2.5 \mathrm{~m}^{-1}$. The results were obtained using the 490 -model and measurements in $1995-2000$.

and sometimes rather high, more than $30 \%$ (Fig. 2a). Probably, the fluctuations in RE curves are caused mainly by fluctuations of measured irradiance spectra (the mean values of RE were determined on the basis of only 3-11 spectra). Figure $2 \mathrm{~b}$ shows that for lakes where $K_{\mathrm{d}, \mathrm{PAR}}>2.5 \mathrm{~m}^{-1}$ (Table 2) the values of $\mathrm{RE}$ in the blue region are from $-10 \%$ to $6 \%$. In the interval $560-700 \mathrm{~nm}$ for three turbid lakes (L. Tuusulanjärvi, L. Võrtsjärv, and L. Ülemiste) RE is from $-10 \%$ to $14 \%$, but for lakes with high concentrations of dissolved organic matter (L. Valkeakotinen and L. Pääjärvi) RE is negative and can be even $-40 \%$. The corresponding spectra of the mean absolute error (AE) for six lakes are presented in Fig. 3. Of course, the lowest values of $\mathrm{AE}$ (from $-0.5 \mathrm{~m}^{-1}$ to $0.4 \mathrm{~m}^{-1}$ ) are 


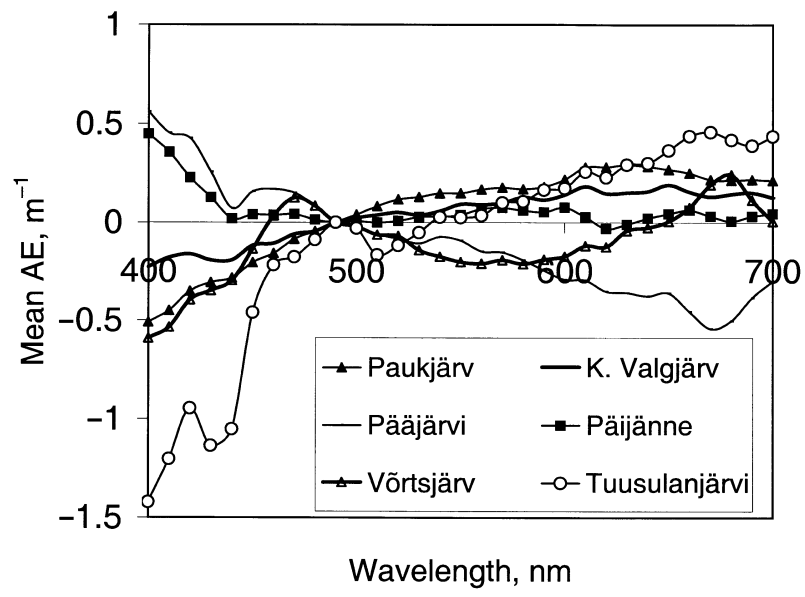

Fig. 3. Spectral distribution of mean values of the absolute error, AE (Eq. 7), calculated separately for 6 lakes. The results were obtained using the 490-model and measurements in 1995-2000.

observed for clear-water lakes (L. Koorküla Valgjärv, L. Päijänne, L. Paukjärv). The absolute errors of other lakes are mostly between $-0.6 \mathrm{~m}^{-1}$ and $0.6 \mathrm{~m}^{-1}$, except L. Tuusulanjärvi in the region $400-440 \mathrm{~nm}$, where $\mathrm{AE}$ can be even $-1.4 \mathrm{~m}^{-1}$. Note that there are some cases in turbid lakes where $K_{\mathrm{d}, \lambda}$ (meas) values in the region of 400-430 nm were determined using extrapolation (the irradiance values were below the sensitivity limit of the LI-1800 UW), and thus the respective errors can be only approximate.

We found many individual cases where the results obtained using the 490-model were in good accordance with the measured values in the whole PAR region, but often some discrepancies in the blue and red regions were observed (Figs 2 and 3). Usually an overestimation of $K_{\mathrm{d}, \lambda}$ in the blue region is accompanied by an underestimation of $K_{\mathrm{d}, \lambda}$ in the red region, and vice versa. The character of these discrepancies leads to the conclusion that when computing the values of the diffuse attenuation coefficient averaged over PAR, the measured and modelled values of the data should be very close (errors in the blue and red regions compensate for each other). Indeed, the correlation $K_{\mathrm{d}, \mathrm{PAR}}$ (meas) vs. $K_{\mathrm{d}, \mathrm{PAR}}$ (490-model), presented in Fig. 4, gives the regression formula $y=0.981 x$, the value of the determination coefficient $R^{2}=0.995$, the standard error is $0.108 \mathrm{~m}^{-1}$, and $p$-level $<0.00002$ (data of 1995, 1997, and 1999-2000 together).

These results lead to the conclusion that the 490-model allows determination of reliable values of $K_{\mathrm{d}, \mathrm{PAR}}$, and in some cases it gives a good description of the spectrum of $K_{\mathrm{d}, \lambda}$. Thus, the 490-model is applicable in conjunction with satellite images (as mentioned before SeaWiFS and MODIS provide $K_{\mathrm{d}}(490)$ as a standard Level 2 product). Even though the spatial resolution of SeaWiFS and MODIS is too coarse for most of the lakes studied by us, their data could be used over the Baltic Sea and larger lakes (Reinart et al., 2002; Ohde et al., 2004). 


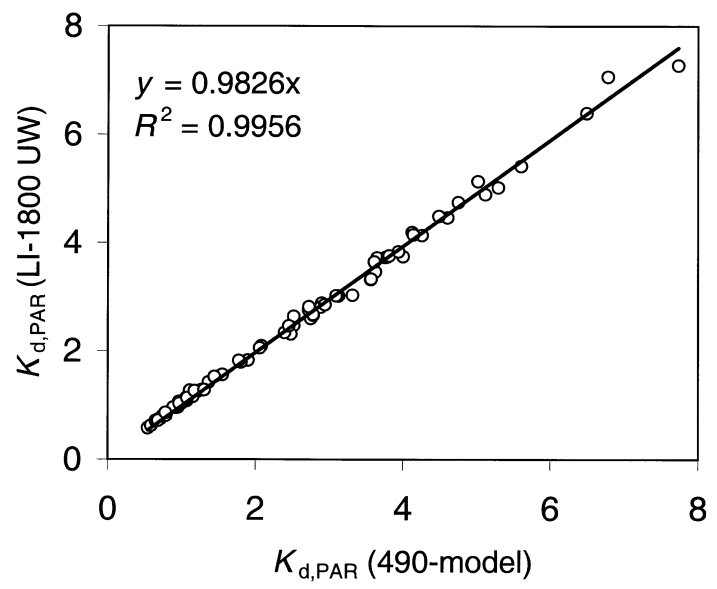

Fig. 4. Correlation between integrated over the interval 400-700 nm (PAR region) diffuse attenuation coefficients, $K_{\mathrm{d}, \mathrm{PAR}}$ (meas) and $K_{\mathrm{d}, \mathrm{PAR}}$ (490-model). $N=83$, significance $p<0.0001$.

\section{Comparison of $K_{\mathrm{d}, \lambda}$ derived from LI-1800 UW and ac-9 measurements}

When doing this comparison, we have to pay attention not only to the reliability of the data obtained by the model but also to the measurements (LI-1800 UW and ac-9). Possibly some values of $K_{\mathrm{d}, \lambda}$ derived from LI-1800 UW data are not truthful (measurements in the conditions of undulation, very small values of $E_{\mathrm{d}, \lambda}$ in the blue region of the spectrum in lakes with low transparency, and also possible technical errors). It is also known that the instrument ac-9 is not recommended for use in very turbid waters. Thus, our next step was to compare the values of $K_{\mathrm{d}, \lambda}$ derived from LI-1800 UW and ac-9 data. The comparison was made for the wavelengths 412,510 , and $650 \mathrm{~nm}$. The lakes for which we have simultaneous ac- 9 results are shown in Table 2.

The correlations obtained using Eqs 11 and 12 are presented in Fig. 5. We can see that at the wavelength of $412 \mathrm{~nm}$ the two methods give rather close results with high values of the determination coefficient $R^{2}$. At the wavelength of $510 \mathrm{~nm}$ the trendline of $K_{\mathrm{d}, \lambda}$ computed by Eq. 12 almost coincides with the 1:1 line, but the value of $R^{2}$ is slightly lower than that obtained with Eq. 11. When $K_{\mathrm{d}, \lambda}<3$, Eq. 11 gives good coincidence of $K_{\mathrm{d}, \lambda}$ obtained on the basis of ac-9 and LI-1800 UW, but for turbid waters $K_{\mathrm{d}, \lambda}(\mathrm{ac}-9)<K_{\mathrm{d}, \lambda}(\mathrm{LI}-1800 \mathrm{UW})$. At the wavelength of $650 \mathrm{~nm}$, similarly to the results for $510 \mathrm{~nm}$, Eq. 11 gives lower values than LI-1800 UW, and differences increase with increasing $K_{\mathrm{d}, \lambda}$. Note that at this wavelength the determination coefficient for both methods is much lower than it was at 412 and $510 \mathrm{~nm}$ (Fig. 5). 


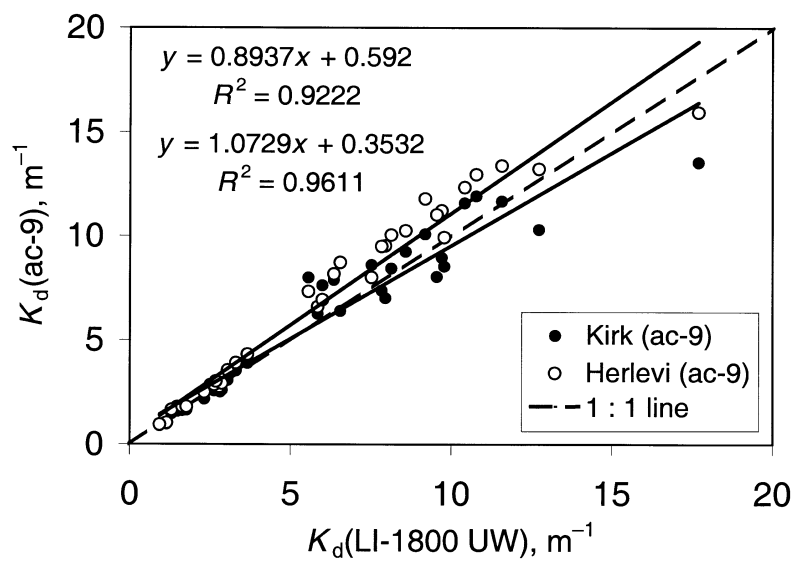

(a)

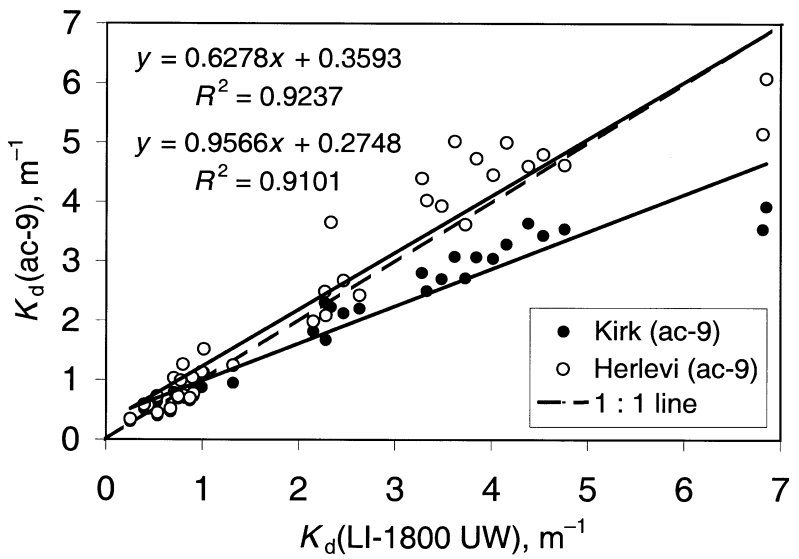

(b)

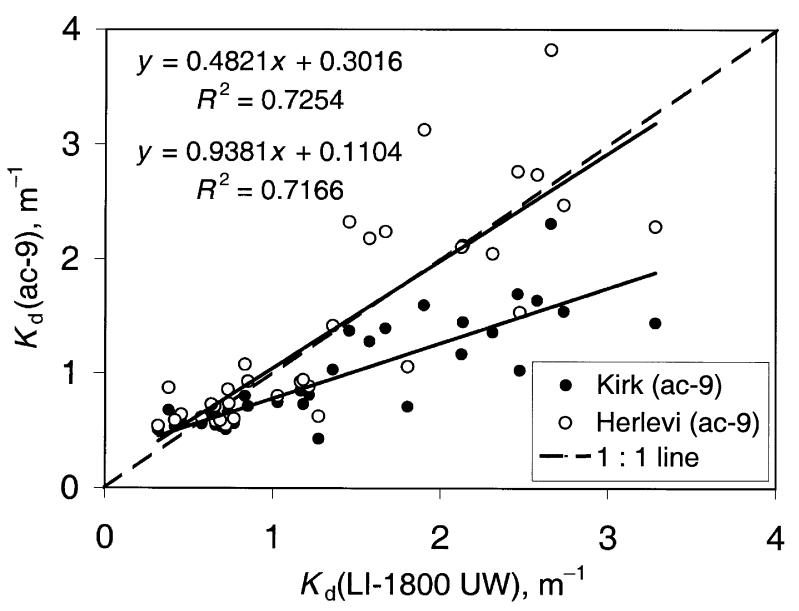

(c)

Fig. 5. Correlations $K_{\mathrm{d}, \lambda}\left(\right.$ ac-9) vs. $K_{\mathrm{d}, \lambda}(\mathrm{LI}-1800 \mathrm{UW})$ : (a) at $412 \mathrm{~nm}$, (b) at $510 \mathrm{~nm}$, (c) at $650 \mathrm{~nm}$. The values of $K_{\mathrm{d}, \lambda}($ ac-9) were calculated using Eq. 11 as well as Eq. $12 . N=37$, significance $p<0.005$. 
These data imply (analogously with Herlevi, 2002) that probably Kirk's $(1989,1996)$ formulas are not suitable for turbid waters. However, assuming that both measurement data are reliable, it is hard to explain why Kirk's formula (Eq. 11) brings about an increase in errors with wavelength. As mentioned before, the constants of Eq. 12 depend on the value of $c_{\lambda}$. This explains the good coincidence of the trendlines by Herlevi and the 1:1 line in Fig. 5. The calculations by Eq. 12 are rather complicated, because even for one and the same spectrum the constants $B$ and $C$ can change when the wavelength changes. The other possibility, that is the use of the tabulated data on the dependence of $B$ and $C$ on the water type (Herlevi, 2002), requires data allowing classification of the lakes in each individual case.

\section{Model for recreating $K_{\mathrm{d}, \lambda}$ spectra on the basis of three reference wavelengths}

As mentioned before, we elaborated a method for the recreation of the spectrum of $K_{\mathrm{d}, \lambda}$ on the basis of its values at three wavelengths (we chose 412, 555 , and $665 \mathrm{~nm})$. It means that in addition to the "one-point" $(490 \mathrm{~nm})$ model of Reinart \& Herlevi (1999) we will have a "three-point" model. To get the necessary information, the spectra of $K_{\mathrm{d}, \lambda}$ were computed according to Eq. 5 taking first $\lambda_{\mathrm{r}}=412$, then $\lambda_{\mathrm{r}}=555$, and $\lambda_{\mathrm{r}}=665 \mathrm{~nm}$ (respectively 412-model, 555-model, and 665 -model). As the parameters $J\left(\lambda_{\mathrm{r}}\right)$ and $M\left(\lambda_{\mathrm{r}}\right)$ were presented with a $10 \mathrm{~nm}$ step (Table 1 ), the necessary values of these parameters were determined by linear interpolation. Then three different spectra were derived according to each $\lambda_{\mathrm{r}}$. An example of these results (together with the corresponding measured spectrum) for L. Koorküla Valgjärv is shown in Fig. 6. As can be expected, the first reference wavelength gives best coincidence with the measured spectra in the band of $400-440 \mathrm{~nm}$, the second in $520-600 \mathrm{~nm}$, and the third in $640-700 \mathrm{~nm}$. This leads to the idea to create a computing program where in some wavebands the results by the model of Reinart \& Herlevi (1999) are used, but in the "intermediate wavebands" the values of $K_{\mathrm{d}, \lambda}$ should be determined as a function of $K_{\mathrm{d}, \lambda}$ for two neighbouring wavebands. Let us name the new, "combined" model the C-model. At present we have for the $\mathrm{C}$-model the following computing system:

(1) Interval $400-435 \mathrm{~nm}$ : take $K_{\mathrm{d}, \lambda}$ obtained from the 412-model.

(2) Interval $435-525 \mathrm{~nm}$ :

$$
K_{\mathrm{d}, \lambda}=\left[0.5+0.01(480-\lambda) K_{\mathrm{d}, \lambda}\left(\lambda_{\mathrm{r}}=412\right)\right]+\left[0.5-0.01(480-\lambda) K_{\mathrm{d}, \lambda}\left(\lambda_{\mathrm{r}}=555\right)\right] .
$$

(3) Interval $525-595 \mathrm{~nm}$ : take $K_{\mathrm{d}, \lambda}$ obtained from the 555 -model.

(4) Interval 595-655 nm:

$$
K_{\mathrm{d}, \lambda}=\left[0.5+0.01(640-\lambda) K_{\mathrm{d}, \lambda}\left(\lambda_{\mathrm{r}}=555\right)\right]+\left[0.5-0.01(640-\lambda) K_{\mathrm{d}, \lambda}\left(\lambda_{\mathrm{r}}=665\right)\right] .
$$

(5) Interval $655-700 \mathrm{~nm}$ : take $K_{\mathrm{d}, \lambda}$ obtained from the 665 -model. 


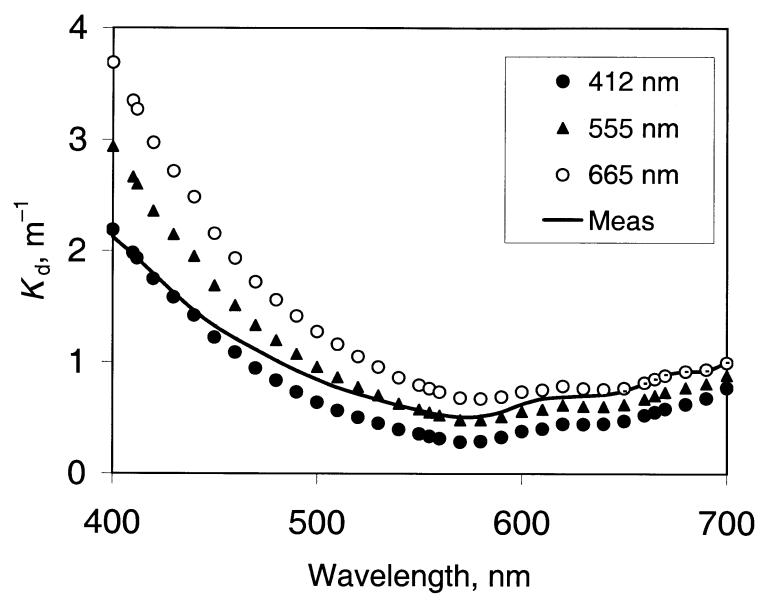

Fig. 6. Comparison of the $K_{\mathrm{d}, \lambda}$ spectra derived from LI-1800 UW measurements and calculated by Eq. 5 taking $\lambda_{\mathrm{r}}$ equal to $412 \mathrm{~nm}, 555 \mathrm{~nm}$, and $665 \mathrm{~nm}$. Measurements were performed in Lake Koorküla Valgjärv 17.06.97.

Even though the C-model seems to be complicated in comparison with the 490-model, it does not require more time for calculations. Some examples describing the spectra of $K_{\mathrm{d}, \lambda}$ obtained using the 490-model, the C-model, and the respective results derived from LI-1800 UW measurements are shown in Fig. 7. From the four spectra shown in Figs $7 \mathrm{a}, \mathrm{b}$ three demonstrate the case where the C-model gives values very close to the measured ones, but where the 490-model does not work so well in the blue and red regions of spectra (lakes Pääjärvi, Tuusulanjärvi, and Verevi). For L. Vesijärvi not only the C-model spectra are close to the measured ones, but also the 490-model gives good results (absolute errors are very low). However, sometimes low absolute errors correspond to rather high relative errors, as is seen when comparing the 490-model spectra with the measured ones (L. Paukjärv in Fig. 7c). There were 14 cases where all five models gave extremely good coincidence with the measured spectrum.

A rather complete picture of the suitability of the C-model for recreating the spectra of $K_{\mathrm{d}, \lambda}$ is given in Table 3, where the statistical characteristics of the correlation $K_{\mathrm{d}, \lambda}$ (meas) vs. $K_{\mathrm{d}, \lambda}(\mathrm{C}$-model $)$ are presented. For determining the regression formulas and other statistical characteristics the Microsoft's Excel statistical analysis tool "Data analysis" was used, and the mean absolute and relative errors were found using Eqs 6-9. The mean values of absolute errors (AE) were very small (between -0.039 and $0.051 \mathrm{~m}^{-1}$ ) and these results are not shown in Table 3. We can see that the coefficients of the regression formulas for all wavelengths are very close to $1, R^{2}>0.98, \mathrm{AAE}$ and $\mathrm{RE}$ are small, and ARE varies from $2 \%$ to $9 \%$. Naturally, at the wavelengths 412,555 , and $665 \mathrm{~nm}$ the values of errors were equal to zero. Performing integration from 400 to $700 \mathrm{~nm}$, we can 


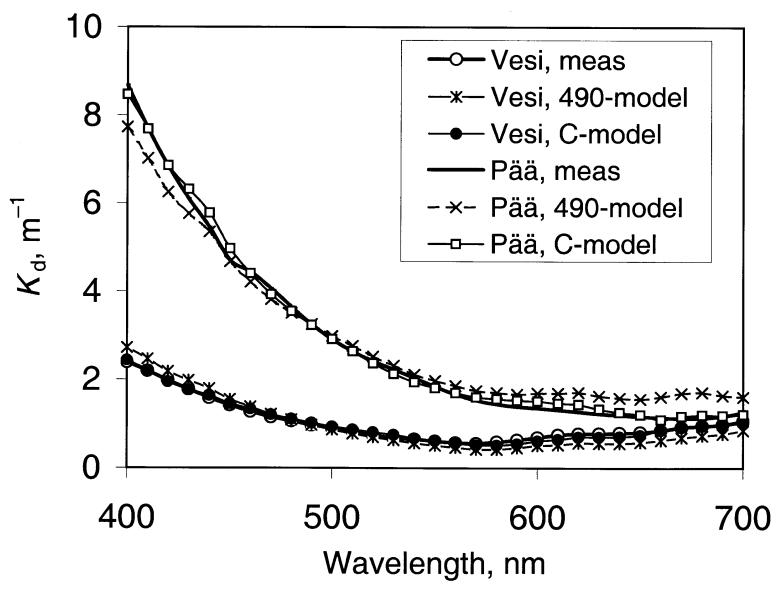

(a)

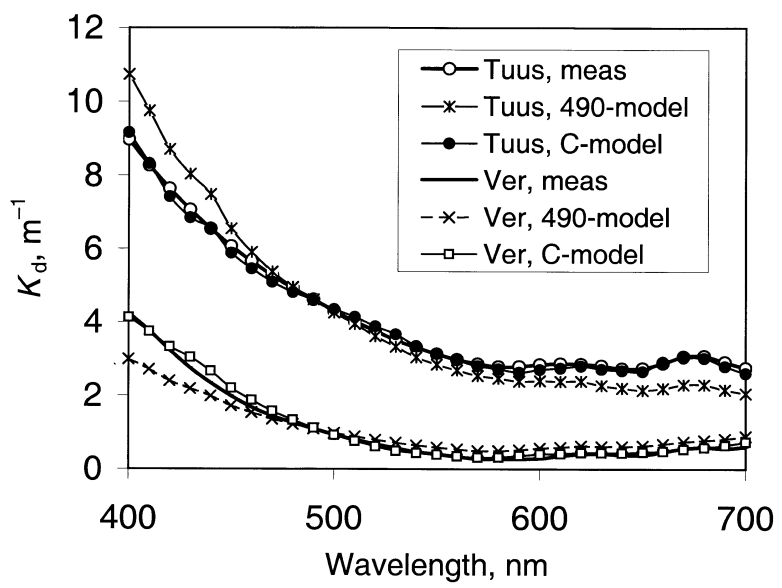

(b)

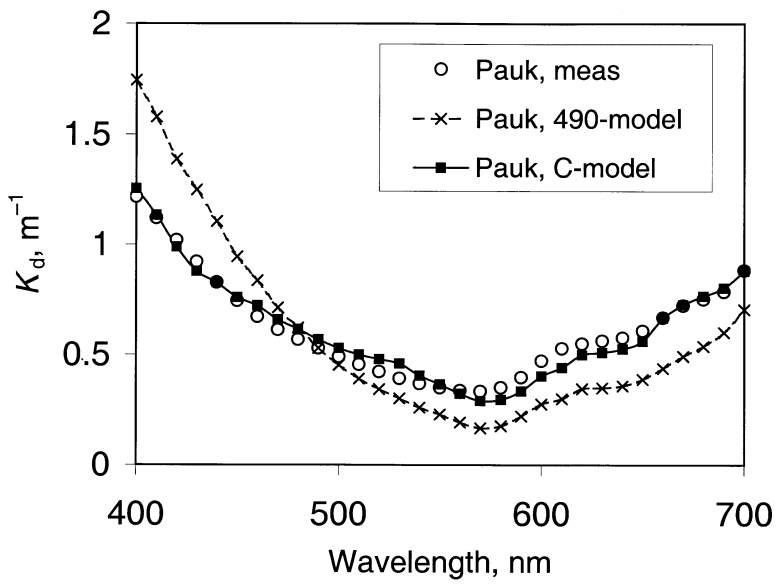

(c)

Fig. 7. Some examples of $K_{\mathrm{d}, \lambda}$ spectra derived from LI-1800 UW measurements and obtained from model calculations (490-model and C-model): (a) for L. Vesijärvi 24.08.95 and L. Lammi Pääjärvi 24.05.00, (b) for L. Tuusulanjärvi 17.08.99 and L. Verevi 06.08.97, (c) for L. Paukjärv 15.06.97. 
Table 3. Statistical characteristics of the regression $K_{\mathrm{d}, \lambda}$ (meas) vs. $K_{\mathrm{d}, \lambda}(\mathrm{C}$-model) determined for 14 wavelengths (including reference wavelengths 412,555 , and $665 \mathrm{~nm}$ ) in the PAR region of the spectrum (the regression formula is $y=D x$, the intercept was taken equal to zero). For all wavelengths $N=84$ and significance $p<10^{-71}$. The errors AAE, RE, and ARE are calculated by Eqs 7-9

\begin{tabular}{c|cccccccc}
\hline$\lambda, \mathrm{nm}$ & $\begin{array}{c}\text { Regression } \\
\text { formula }\end{array}$ & $R^{2}$ & $\mathrm{SE}, \mathrm{m}^{-1}$ & $\mathrm{AAE}, \mathrm{m}^{-1}$ & $\mathrm{RE}$ & $\mathrm{ARE}$ \\
\hline 400 & $y=0.998 x$ & 0.998 & 0.153 & 0.089 & 0.003 & 0.020 \\
412 & $y=x$ & 1 & 0 & 0 & 0 & 0 \\
430 & $y=0.990 x$ & 0.995 & 0.207 & 0.138 & -0.016 & 0.038 \\
460 & $y=1.016 x$ & 0.990 & 0.219 & 0.156 & -0.025 & 0.063 \\
490 & $y=1.012 x$ & 0.992 & 0.161 & 0.114 & -0.023 & 0.060 \\
520 & $y=0.993 x$ & 0.994 & 0.112 & 0.075 & -0.032 & 0.062 \\
550 & $y=0.997 x$ & 0.997 & 0.063 & 0.027 & -0.011 & 0.025 \\
555 & $y=x$ & 1 & 0 & 0 & 0 & 0 \\
580 & $y=0.989 x$ & 0.987 & 0.114 & 0.082 & 0.013 & 0.085 \\
610 & $y=1.007 x$ & 0.977 & 0.144 & 0.100 & 0.021 & 0.087 \\
640 & $y=1.001 x$ & 0.987 & 0.099 & 0.070 & -0.003 & 0.058 \\
665 & $y=x$ & 1 & 0 & 0 & 0 & 0 \\
670 & $y=1.004 x$ & 0.997 & 0.047 & 0.032 & -0.009 & 0.025 \\
700 & $y=0.997 x$ & 0.981 & 0.093 & 0.067 & -0.006 & 0.052
\end{tabular}

compare the values $K_{\mathrm{d}, \mathrm{PAR}}$ (meas) and $K_{\mathrm{d}, \mathrm{PAR}}(\mathrm{C}$-model). The regression formula is $y=1.001 x, R^{2}=0.9986$, and the standard error is $0.0604 \mathrm{~m}^{-1}$. As mentioned before, also the 490-model was quite suitable for determining the integrated value of diffuse attenuation coefficient $K_{\mathrm{d}, \mathrm{PAR}}$.

We studied also the possibility of describing $K_{\mathrm{d}, \lambda}$ spectra by the C-model using $K_{\mathrm{d}, \lambda}$ values for three reference wavelengths derived from ac-9 measurements. The reference wavelengths, corresponding to three channels of ac-9, were 412,510 , and $676 \mathrm{~nm}$. It occurred that the principles of the computing scheme applied in the C-model for BIC-2104 channels work rather satisfactorily also in the case of ac-9. However, due to different reference wavelengths, it was necessary to change some numerical values in the computing scheme.

One can ask whether the model based on the $K_{\mathrm{d}, \lambda}$ values at three wavelengths (like the C-model) is necessary at all, because we can try to recreate the spectra in the form of a trendline through three (reference) points. Our studies showed that in the region 400-580 $\mathrm{nm}$ at least three trendlines (power function, exponential, and square polynom) describe these spectra rather well, but at longer wavelengths the differences can be notable (depending on water type). Two examples are shown in Fig. 8. First the values of $K_{\mathrm{d}, \lambda}$ at 400, 490, and $580 \mathrm{~nm}$ (measured by the LI-1800 UW) for two lakes (Võrtsjärv and Vesijärvi) were placed in a figure, then three trendlines (power function, exponential, and square polynom) were 


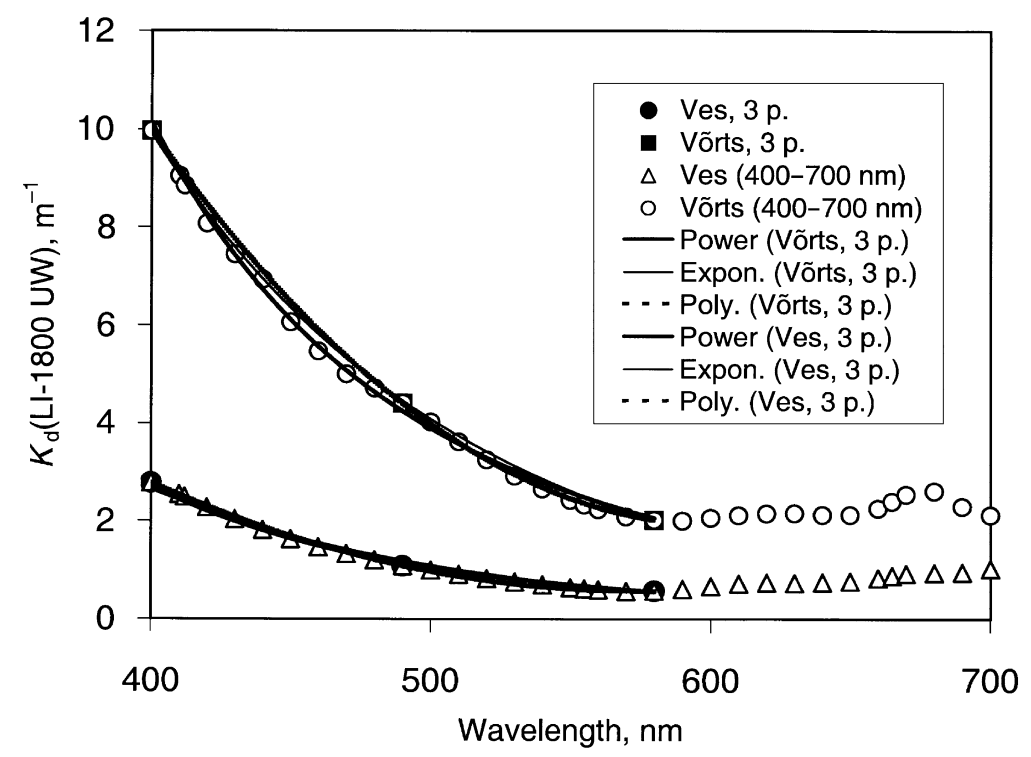

Fig. 8. Suitability of different trendlines for the approximation of $K_{\mathrm{d}, \lambda}$ spectra in the region 400-580 nm. Data were obtained for Lake Vesijärvi 01.06.95 and Lake Võrtsjärv 06.06.00. The corresponding regression formulas and $R^{2}$ values are shown in Table 4.

Table 4. Regression formulas and the values of $R^{2}$ obtained by trendlines of different type drawn on the basis of three points: $K_{\mathrm{d}}(400), K_{\mathrm{d}}(490)$, and $K_{\mathrm{d}}(580)$

\begin{tabular}{rllll}
\hline Lake and time & \multicolumn{1}{c}{ Type } & \multicolumn{1}{c}{ Regression formula } & $R^{2}$ \\
\hline Vesijärvi, 01.06.95 & Power & $K_{\mathrm{d}}=3.38 \mathrm{E}+11 \lambda^{-4.26}$ & 0.997 \\
& Exponential & $K_{\mathrm{d}}=88.4 \exp (-0.00877 \lambda)$ & 0.988 \\
& Square polynom & $K_{\mathrm{d}}=7.31 \mathrm{E}-05 \lambda^{2}-0.084 \lambda+24.6$ & 1.000 \\
Võrtsjärv, 06.06.00 & Power & $K_{\mathrm{d}}=1.45 \mathrm{E}+12 \lambda^{-4.29}$ & 0.998 \\
& Exponential & $K_{\mathrm{d}}=344 \exp (-0.00887 \lambda)$ & 1.000 \\
& Square polynom & $K_{\mathrm{d}}=1.96 \mathrm{E}-04 \lambda^{2}-0.237 \lambda+73.2$ & 1.000
\end{tabular}

drawn through these points. For comparison the corresponding $K_{\mathrm{d}, \lambda}$ spectra (with an interval of $10 \mathrm{~nm}$ ) in the PAR region are also presented in Fig. 8. The regression formulas and the values of $R^{2}$ are shown in Table 4. We can see that $R^{2}$ varies from 0.988 to 1 and that in the region $400-580 \mathrm{~nm}$ the most suitable trendline seems to be a square polynom.

The results obtained in our study show that the C-model (relying on the measured data at three wavelengths) enables not only to determine $K_{\mathrm{d} \text {,PAR }}$, but also to reconstruct the spectra of $K_{\mathrm{d}, \lambda}$ with high accuracy. Of course, the initial 
data ( $K_{\mathrm{d}, \lambda}$ at the reference wavelengths) have to be reliable. Note also that both the 490-model and the C-model are created on the basis of the underwater measurements by a spectrometer LI-1800 UW and influenced by the reliability of these results. It should be of interest to reconstruct the $K_{\mathrm{d}, \lambda}$ spectra using actual measurements for three wavebands by the instrument BIC-2104 (or by some other instrument) and to compare the results with those obtained with some modern spectrophotometer (other than LI-1800 UW). We plan to perform it in the future.

\section{CONCLUSIONS}

The 490-model (Reinart \& Herlevi, 1999) allows determination of reliable values of $K_{\mathrm{d}, \mathrm{PAR}}\left(y=0.983 x, R^{2}=0.996\right)$ and description of the diffuse attenuation coefficient spectrum in many lakes. Comparison of the results obtained by Reinart and Herlevi in 1995 and 1997 with new measurements (1999-2000) leads to the conclusion that there is no need to recalculate the coefficients of the model.

Comparison of $K_{\mathrm{d}, \lambda}$ derived from LI-1800 UW and ac-9 measurements (in the last case two different calculation methods were used) implies that the suitability of Kirk's $(1989,1996)$ formulas for turbid waters is disputable. However, also the measurement results obtained by both instruments can be incorrect, especially in very turbid lakes (systematical errors and/or errors connected with measurement conditions). Thus, to draw final quantitative conclusions additional studies are needed.

We elaborated a new method (named C-model) that enables to recreate the spectrum of $K_{\mathrm{d}, \lambda}$ on the basis on its measured values at three wavelengths, for which we chose the centres of three wavebands of the instrument BIC-2104 $(412,555$, and $665 \mathrm{~nm})$. When applying this model, the following scheme has to be used: (1) in the spectral intervals that are close to the reference wavelength, the results should be obtained on the basis of the "one-point" model and (2) in the "intermediate wavebands" the values of $K_{\mathrm{d}, \lambda}$ should be determined as a function of $K_{\mathrm{d}, \lambda}$ for two neighbouring wavebands.

The reliability of the $\mathrm{C}$-model was assessed by determining regression formulas and statistical characteristics of the correlation $K_{\mathrm{d}, \lambda}$ (meas) vs. $K_{\mathrm{d}, \lambda}(\mathrm{C}-$ model $)$ for 11 wavelengths between 400 and $700 \mathrm{~nm}$. The coefficient $D$ in the regression formula $y=D x$ varied between 0.989 and 1.016 , the determination coefficient $R^{2}$ from 0.977 to 0.998 , and the standard error from 0.047 to $0.219 \mathrm{~m}^{-1}$. Comparison of the values $K_{\mathrm{d}, \mathrm{PAR}}$ (meas) and $K_{\mathrm{d}, \mathrm{PAR}}(\mathrm{C}-$ model) gave the regression formula $y=1.001 x, R^{2}=0.999$, and standard error $=0.0604 \mathrm{~m}^{-1}$. Thus, our C-model enables to determine $K_{\mathrm{d}, \mathrm{PAR}}$, and also to reconstruct the spectra of $K_{\mathrm{d}, \lambda}$ with high reliability. Of course, the initial data ( $K_{\mathrm{d}, \lambda}$ at the reference wavelengths) have to be truthful. 


\section{ACKNOWLEDGEMENTS}

The authors are indebted to the Estonian Science Foundation (grant No. 5594) and to the Academy of Finland for financial support of this investigation. This study was supported also by EU Marie Curie Reintegration Fellowship, contract No. MERG-CT-2004-004401.

\section{REFERENCES}

Arst, H. 2003. Optical Properties and Remote Sensing of Multicomponental Water Bodies. Springer, Praxis-Publishing, Chichester, U.K.

Arst, H., Erm, A., Kallaste, K., Mäekivi, S., Reinart, A., Nõges, P. \& Nõges, T. 1999. Investigation of Estonian and Finnish lakes by optical measurements in 1992-97. Proc. Estonian Acad. Sci. Biol. Ecol., 48, 5-24.

Arst, H., Reinart, A., Erm, A. \& Hussainov, M. 2000. Influence of depth-dependence of the PAR diffuse attenuation coefficient on the computation of downward irradiance in different water bodies. Geophysica, 36, 129-139.

Arst, H., Erm, A., Reinart, A., Sipelgas, L. \& Herlevi, A. 2002. Calculating irradiance penetration into water bodies from the measured beam attenuation coefficient II: Application of improved model to different types of lakes. Nord. Hydrol., 33, 207-226.

Austin, R. W. \& Petzold, T. J. 1986. Spectral dependence of the diffuse attenuation coefficient of light in ocean waters. Opt. Eng., 25(30), 471-479.

Chow-Fraser, P. 1998. A conceptual ecological model to aid restoration of Cootes Paradise Marsh, a degraded coastal wetland of L. Ontario, Canada. Wetland Ecol. Manage., 6, 43-57.

Dera, J. 1992. Marine Physics. PWN, Warszawa and Elsevier, Amsterdam.

Gallegos, Ch. L., Correll, D. L. \& Pierce, J. W. 1990. Modeling spectral diffuse attenuation, absorption, and scattering coefficients in a turbid estuary. Limnol. Oceanogr., 35, 1486-1502.

Herlevi, A. 2002. Inherent and apparent optical properties in relation to water quality in Nordic waters. Academic dissertation in Geophysics. Rep. Ser. Geophys., 45, University of Helsinki, Finland.

Herlevi, A., Virta, A., Arst, H. \& Erm, A. 1999. Results of light absorption/attenuation measurements in Finnish and Estonian lakes in summer 1997. Proc. Estonian Acad. Sci. Biol. Ecol., 48, 46-62.

Jerlov, N. G. 1968. Optical Oceanography. Elsevier Oceanography, Amsterdam.

Kirk, J. T. O. 1981. A Monte Carlo study of the nature of the underwater light field in, and the relationships between optical properties of, turbid yellow waters. Aust. J. Mar. Freshwater Res., 32, 517-532.

Kirk, J. T. O. 1989. The assessment and prediction of optical water quality. In Australian Water and Wastewater Assoc. 13th Fed. Convention, Canberra 6-10 March, 1989, Barton, pp. 504507.

Kirk, J. T. O. 1996. Light \& Photosynthesis in Aquatic Ecosystems. Cambridge University Press.

Kyewalyanga, M., Platt, T. \& Sathyendranath, S. 1992. Ocean primary production calculated by spectral and broad-band models. Mar. Ecol. Prog. Ser., 85, 171-185.

LI-COR, Inc. 1984. LI-1800 UW, Underwater Spectral Instruction Manual. Lincoln, Nebraska, USA.

Mobley, C. D. 1994. Light in Water-Radiative Transfer in Natural Waters. Academic Press, San Diego.

Ohde, T. B., Sturm, H. \& Siegel, H. 2004, Preliminary results for SeaWiFS vicarious calibration coefficients in the Baltic Sea. Intn. J. Rem. Sens., 25, 1495-1499. 
Platt, T., Lewis, M. \& Geider, R. 1984. Thermodynamics of the pelagic ecosystem: elementary closure conditions for biological production in the open ocean. In Flows of Energy and Materials in Marine Ecosystems. NATO Conf. Ser., 4, Mar. Sci. V. 13, Plenum, 49-84.

Preisendorfer, R. W. 1961. Application of radiative transfer theory to light measurements in the sea. Union Geod. Geoph. Inst. Monogr., 10, 11-29.

Reinart, A. \& Herlevi, A. 1999. Diffuse attenuation coefficient in some Estonian and Finnish lakes. Proc. Estonian Acad. Sci. Biol. Ecol., 48, 267-283.

Reinart, A., Pierson, D. \& Land, P. 2002. Large European lakes in SeaWIFS and MODIS images. Proc. Ocean Opt., XVI, CD-ROM.

Reinart, A., Paavel, B. \& Tuvikene, L. 2004. Effect of coloured dissolved organic matter on the attenuation of photosynthetically active radiation in Lake Peipsi. Proc. Estonian Acad. Sci. Biol. Ecol., 53, 88-105.

Sathyendranath, S., Platt, T., Caverhill, C. M., Warnock, R. E. \& Lewis, M. R. 1989. Remote sensing of oceanic primary production: computations using a spectral model. Deep-Sea Res., 36, 431-453.

Smith, R. C., Prezelin, B. B., Bidigare, R. R. \& Baker, K. S. 1989. Bio-optical modeling of photosynthetic production in coastal waters. Limnol. Oceanogr., 34, 1524-1544.

Stefan, H. G., Fang, X. \& Hondzo, M. 1998. Simulated climate change effects on year-round water temperatures in temperate zone lakes. Clim. Change, 40, 547-576.

WET Labs, Inc. 1995. AC-9 User's Manual. Version 1.0. Philomath, OR, USA.

\title{
Valguse difuusse nõrgenemiskoefitsiendi mudelarvutused järvevete jaoks
}

\author{
Birgot Paavel, Helgi Arst, Anu Reinart ja Antti Herlevi
}

Andmed päikesekiirguse spektraalse jaotuse kohta vees on vajalikud optilises kaugseires, vees leiduvate lisaainete tuvastamisel ja merebioloogias. Kiirguse nõrgenemist sügavusega iseloomustab difuusne nõrgenemiskoefitsient $\left(K_{\mathrm{d}}, \lambda\right)$, mille alusel saab leida kiirguse vertikaalsed profiilid vees. On juhtumeid, kus mõõtmisandmed on olemas vaid ühe või mõne spektririba jaoks. Artiklis on testitud ja täiustatud mudeleid, mis on välja töötatud $K_{\mathrm{d}, \lambda}$ spektrite määramiseks fotosünteetiliselt aktiivses spektripiirkonnas (PAR, vahemikus 400-700 nm), kui mõõtmisandmed on olemas 1-3 lainepikkuse jaoks. Aastatel 1995 ja 1997 tehtud veealuse kiiritustiheduse spektraalsete mõõtmiste baasil on A. Reinarti ja A. Herlevi (1999) poolt välja töötatud ühepunktimudel, mis on arvuliselt realiseeritud, võttes aluseks $K_{\mathrm{d}, \lambda}$ andmed lainepikkuse $490 \mathrm{~nm}$ jaoks. Uute mõõtmiste (1999-2000) baasil on testitud selle mudeli koefitsiente, mis on osutunud adekvaatseteks. Uue versioonina on käesolevas töös välja töötatud nn C-mudel, mis kasutab algandmetena veealuse spektromeetri BIC-2104 kolme kanali (412, 555 ja $665 \mathrm{~nm}$ ) mõõtmisandmetest saadud $K_{\mathrm{d}, \lambda}$ väärtusi. C-mudelit on hinnatud statistilise analüüsi abil ja osutub, et see võimaldab saada $K_{\mathrm{d}, \lambda}$ spektreid, mis on väga lähedased mõõdetutele. Vahemiku 400-700 nm piires keskmistatud difuusse nõrgenemiskoefitsiendi väärtusi on aga suure täpsusega võimalik määrata mõlema mudeli abil. 